\title{
Transformational Leadership Inspired Extra Effort: The Mediating Role of Individual Consideration of the Coach-Athlete Relationship in College Basketball Players
}

\author{
Recep Gorgulu \\ Elite Performance in Sport Research Group, Faculty of Sport Sciences, Bursa Uludag University, Turkey
}

Copyright(C2019 by authors, all rights reserved. Authors agree that this article remains permanently open access under the terms of the Creative Commons Attribution License 4.0 International License

\begin{abstract}
Transformational leadership has been shown to impact a wide range of outcomes in sport. Previously, researchers have begun to examine the mechanisms by which transformational leadership exerts its impact on followers. However, there is still little known about the mediating variables between transformational leadership and followers' performance. Therefore, the aim of the current study was to examine the relationship between transformational leadership and the leader-inspired extra effort with the potential mediating role of the coach-athlete relationship in college basketball players. The differentiated transformational leadership inventory (DTLI) was used to assess college coaches' leadership behaviours and the coach-athlete relationship questionnaire (CART-Q) was used to examine the athletes' perceptions of the relationship with their current coach. Accordingly, the leader-inspired extra effort scale (LIEE) was used to investigate the college basketball players' perception of their effort. The sample comprised 78 college basketball players (43 men, 35 women; $M_{\text {age }}=21.60, S D=$ $3.05)$. Results did not provide support for full mediation except the direct effects between individual consideration and leader-inspired extra effort had a significant relationship $(\beta=.491 ; S E=.143, p<0.01)$ as well as the individual consideration and the closeness $(\beta=.069 ; S E$ $=.101, p<0.01)$. The results highlight that coaches and educators should endeavour to display transformational leadership behaviours as they are related to coach and athlete relationship on the athletic effort.
\end{abstract}

Keywords Leader, Team, Sport, Performance, Mediation Analyses

\section{Introduction}

Coaches are mostly considered being leaders in sport.
Many researchers used the words coach and leader interchangeably, thereby reinforcing the presumption that the coach is a leader [7]. However, all coaches are not considered as effective leaders. To further understand the characteristics of coaches' leadership style, as researchers have examined successful coaches by assuming that success demonstrates leadership [7]. The importance of leadership studies in the field of education, psychology and sport psychology, has increasingly received a deep attention. Since the late 1970 s, "the multidimensional model [1] and the mediational model (2) of coach leadership have been the main frameworks for studying the behaviours, actions and styles that coaches employ in their coaching process"' [3, p.413]. Several lines of research have developed over recent decades that to articulate specifically the athletes' perception of leader behaviours and it appears to be significantly associated with physical and psychological outcomes for athletes from different ages and levels such as from college level to a professional level of sport [4].

Furthermore, a conceptual framework was advanced by Chellandurai [5] to show that athletes perception of leader behaviours seem to be significantly associated with athletic performance. One interesting line of enquiry might be to examine how coaches' approach could manage any discrepancies among the above and to assess athletes' preferences in respect to leadership style, as well as to evaluate the interaction between coaches and athletes [6]. Later, in the multidimensional model [1] of the leadership, team members' satisfaction and team effort were determinants of the relationship among three states of leader behaviours namely; the actual coach behaviour, preferred coach behaviour by the athletes, and required leader behaviour by the situation [7]. Therefore, the type of leadership behaviours displayed by the coach plays an important role in successful sporting performance [8]. In 
this premise, transformational leadership has been shown to impact a wide range of outcomes in sport [9-12]. In the early stage, researchers have begun to examine the mechanisms by which transformational leadership exerts its impact on followers [10]. More specifically, transformational leadership has defined mediators that have mediated the relationship between transformational leadership behaviours and follower behaviours. For instance, trust in leaders [13] intrinsic motivation [10] and team cohesion [14] have examined in order to emphasize the mediational role of the transformational leadership.

Previous research in sport-related literature mainly focused on the development of leadership, however transformational leadership in sport is still limited [12] and little research has been conducted in this field. More specifically, there is still little known about the mediating processes between transformational leadership and effort $[15,16]$ or sporting performance. In this respect, it would seem prudent to select a possible outcome variable that is central to the theoretical predictions of transformational leadership theory [9] that is the leader-inspired extra effort. Central to the predictions of transformational leadership theory is that transformational leaders would inspire followers to invest extra effort [17]. Furthermore, Bass [18] stated that 'transformational leadership styles build on the transactional base contributing to the extra effort and performance of followers"' (p. 5). Thus, there are number of studies that have examined the impact of transformational leadership on leader-inspired extra effort $(12,17,19-21)$.

However, these studies have all conceptualized transformational leader behaviours as a one-dimensional construct and thereby assumed that all transformational leadership behaviours have a similar impact on their followers. Furthermore, according to Arthur et al., [9] ' 'leader-inspired extra effort is a worthy outcome in its own right given its ability to delineate the motivational consequences that can be attributed to different leader behaviours" (p.6). In the current study, transformational leadership has constructed at two sub-component levels which should have more meaningful interactions with the coach and athlete relationship. It is because leadership is an essential aspect in groups and teams as leaders provide a sense of direction to the team members. Teams or groups that have well-established leadership practices are characterized by having an awareness of the individual needs (e.g., in this case, individual consideration: IC) of the members and they also have strong interpersonal relationships within the group or team.

Beyond the theoretical rationale for inclusion of leader-inspired extra effort to examine the relationship between transformational leadership and leader-inspired extra effort; the objective of the current study was to examine in which transformational behaviour (e.g., individual consideration) effects effort in college basketball through the mediating effects of coach-athlete relationship.

\section{Materials and Methods}

\subsection{Participants}

Before a university team training session, players were approached and invited to participate in the study. The inclusion criteria were that participants train/compete at least once a week throughout the season and they had a coach-athlete relationship of at least 6 months within the same team. The average time athletes had been with their present coach was 1.2 years $(\mathrm{SD}=1.36)$. Data from all participants were excluded from the analysis due to missing data therefore 8 participants were excluded because of the incomplete data set. Therefore, the final sample comprised 78 college basketball players (43men, 35 women; $M_{\text {age }}=21.60, S D=3.05$ ).

\subsection{Measures}

\subsubsection{The Differentiated Transformational Leadership Inventory (DTLI)}

The Differentiated Transformational Leadership Inventory (DTLI), [11] was used to assess coaches' leadership behaviours. The DTLI has 27-items that tap seven different leader behaviours and six of the items are transformational in nature: inspirational motivation (e.g., "My coach talks in a way that makes me believe I can succeed"); appropriate role modelling (e.g., "My coach is a good role model for to me to follow"); fostering acceptance of group goals (e.g., "My coach gets the team to work together for the same goal"); individual consideration (e.g., "My coach recognizes that different athletes have different needs"); intellectual stimulation (e.g., "My coach challenges me to think about problems in new ways"); and high performance expectations (e.g., "My coach always expects us to do our best"); and one transactional behaviour, contingent reward (e.g., "My coach gives me special recognition when I do very good work"). Each item is scored on a 5-point Likert scale anchored by 1 "not at all', 2 'once in a while", 3'sometimes", 4'fairly often' and 5 "all of the time". All the participants were asked to respond to the questionnaire in relation to their coaches and more specifically, how frequently each statement fits their coach's normal behaviour. The internal consistencies of each factor or subscale were assessed via Cronbach's coefficient alpha [22]. In the present study, Cronbach's alpha coefficients for the 'Differentiated Transformational Leadership Inventory"- selected measure-was: individual consideration $\alpha=0.84$. As it can be clearly seen that selected subscale was $>0.70$, which reveals that the constructs were reliable. 


\subsubsection{Coach-Athlete Relationship Questionnaire (CART-Q)}

The Coach and Athlete Relationship Questionnaire (CART-Q), [23] was used to assess the athletes' perceptions of the quality of the relationship with their coach. The instrument has 11 items that are a direct perspective of athletes' perception. The CART-Q measured three positive dimensions of the relationship which namely "closeness" (affective), "commitment" (cognitive) and "'complementarity" (behavioural). Firstly, closeness is a three-item subscale that assesses the level, to which the athlete trusts, respect and appreciates the coach as an example of the items: "I respect my coach". Secondly, commitment is a four-item subscale that assesses athletes' willingness and dedication to maintain the athletic partnership over time and as an example of items: "I am committed to my coach". Lastly, complementarity is a four-item subscale that assesses athletes' co-operative actions and as an example of items: " when I am coached by my coach, I am ready to do my best". The scale ranged from 1 (Not-at all), to 7 (Extremely) with a mid-point 4 (Half-way)" [23]. Cronbach's alpha coefficient for closeness was $\alpha=0.78$ which was greater than 0.70 and was thus deemed as internally reliable.

\subsubsection{Leader-Inspired Extra Effort (LIEE)}

The Leader-Inspired Extra Effort scale was used in the present study. The scale was based on Bass and Avolio's [24] conceptualization within the MLQ-5X. Four new items were developed for the aim of this study to reflect the sporting context of the study (e.g., "My coach motivates me to work hard."). A 5-point Likert scale was used (1-strongly disagree through to 5- strongly agree)", [9]. For the current study, coefficient alpha for leader-inspired extra effort scale was 0.91 and the composite reliability was 0.89 . Similarly, Arthur and colleagues [9] reported 0.89 for the Cronbach alpha coefficient and 0.93 for the composite reliability.

\subsection{Statistical Analyses}

Consistent with the procedures described by Baron and Kenny [25], linear regression analyses were used to examine the individual consideration of coach-athlete relationship as a mediator variable between transformational leadership and leader-inspired extra effort. In order to estimate the mediating effects, Baron and Kenny's [25] procedure was followed in the present study. To support for full mediation, four steps need to be met according to Baron and Kenny [25], these are; a-The independent variable (transformational leadership behaviour; individual consideration) needs to be significantly related to the dependent variable (leader-inspired extra effort), (note: this is also a direct effect). b-The independent variable (i.e., transformational leadership) needs to be significantly related the mediating variable (coach and athlete relationship; closeness). c-The mediator variable (closeness) needs to be significantly related to the dependent variable (leader-inspired extra effort). $c^{\prime}-$ The relationship between independent variable (transformational leadership; individual consideration) and dependent variable (leader-inspired extra effort) must be non-significant when the mediating variable (coach and athlete relationship; closeness) is introduced into the regression equation predicting the dependent variable. In fact, the coefficient between transformational leadership (IV) and leader-inspired extra effort (DV) after introducing coach and athlete relationship (MV) into the regression equation remains significant but is reduced which means that there is an evidence for partial mediation.

\section{Findings}

\subsection{Descriptive Statistics}

The results analyzed with SPSS 22.0 and the analyses of the hypotheses test with bivariate correlations, regression analysis for the mediating variables in the present study are presented in findings. Descriptive statistics, means, standard deviations (SD), correlations and alpha reliabilities in parenthesis were computed for all the variables in the current study (see table 1).

Table 1. Descriptive statistics, internal reliabilities, composite reliabilities in parentheses and correlations between the study variables

\begin{tabular}{cccccccccc}
\hline Variable & Mean & SD & $\mathbf{1}$ & $\mathbf{2}$ & $\mathbf{3}$ & $\mathbf{4}$ & $\mathbf{5}$ & $\mathbf{6}$ & $\mathbf{7}$ \\
\hline 1.Age & 21.6 & 3.05 & $-^{-}$ & & & & & & \\
2.Time with Coach & 1.2 & 1.36 & .04 & $-^{\mathrm{a}}$ & & & & & \\
3.Individual Consideration & 3.8 & .66 & -.05 & $.19^{*}$ & $(.84)$ & & & & \\
4.Appropriate Role Modeling & 3.9 & .89 & .07 & $.17^{*}$ & $.76^{* *}$ & $(.80)$ & & & \\
5. Closeness & 3.2 & .88 & -.08 & .05 & $.71^{* *}$ & .14 & $(.75)$ & & \\
6.Commitment & 2.8 & .80 & -.01 & .13 & -.09 & .07 & $.72^{* *}$ & $(.65)$ & \\
7.Leader Inspired Extra Effort & 3.0 & 1.1 & -.02 & .08 & $.38^{* *}$ & .12 & -.04 & -.08 & $-.05(.89)$ \\
\hline
\end{tabular}

Note. $\mathrm{N}=78,{ }^{*} \mathrm{p}<0.05,{ }^{* *} \mathrm{p}<0.01$. Time with coach is in years. ${ }^{\mathrm{a}}=$ No reliability analysis. 


\subsection{Internal Reliability}

The descriptive statistics obtained from the current study were illustrated in Table 1. The results revealed the Cronbach's alpha reliabilities of the concerned scales exceeded Nunnally's [26] criterion of .70, suggesting that in this study all self-reported measures demonstrated acceptable internal reliability. Most of the alpha coefficients for the transformational leadership sub-components ranged from .70 to .91 and were deemed to be internally reliable based on the criterion of .70 set for the psychological domain [26]. Individual consideration produced alpha reliability of .79 closeness produced alpha reliability of .75 and finally leader-inspired extra effort report alpha reliability of 89 . As a result, these reliabilities (in parentheses) reported well inter-item consistency of respective scales.

\subsection{Zero Order Correlations}

Results revealed that the individual consideration and time with coach $(r=.19, p<.05)$, and appropriate role modeling and time with coach $(r=.17, p<.05)$ were although positively correlated they were rather low. However, the correlation between appropriate role modeling and individual consideration was $(r=.76, p$ $<$.001) positively correlated. The correlation between closeness and individual consideration was also positive $(r$ $=.71, p<.001)$. Similarly, the correlation between commitment and closeness was significantly and positively $(r=.72, p<.001)$ correlated. Lastly, individual consideration and leader-inspired extra effort was positively correlated $(r=.38, p<.001)$.

\subsection{Testing Hypotheses with Mediation Analyses}

In testing the mediating effects, Baron and Kenny's [25] the four-step regression procedure was used to determine whether or not coach and athlete relationship (closeness) is a mediating variable of the relationship between transformational leadership and leader-inspired extra effort. Beta coefficients $(\beta)$, Standard Errors $(S E)$ and R square $\left(R^{2}\right)$ were computed for all the variables in the current study and were presented in Table 2. Regression analysis did not support full mediation except the direct effects between individual consideration and leader-inspired extra effort had significant relationship $(\beta=.491 ; S E=.143, p<0.01)$ and individual consideration and closeness $(\beta=.069 ; S E$ $=.101, p<0.01)$. Contrary to expectation, Table 2 also shows that as a mediator variable closeness did not related to leader-inspired extra effort $(\beta=-.062 ; S E=.210, p>$ $0.01)$. Lastly, there was no significant effect on the leader-inspired extra effort by controlling mediator (closeness) and independent variable (individual consideration), $(\beta=-.112 ; S E=.103, p>0.01)$. To sum, although the relationship between individual consideration and leader-inspired extra effort (direct effect) was significant, closeness was not fully a mediating variable between individual consideration and leader-inspired extra effort of college basketball players.

Table 2. Regression analyses examining the mediation effect of closeness between individual consideration and leader-inspired extra effort.

\begin{tabular}{|c|c|c|c|c|c|c|c|c|c|c|c|c|}
\hline \multirow[t]{2}{*}{ Step } & \multicolumn{2}{|c|}{ a } & \multicolumn{4}{|c|}{ b } & \multicolumn{2}{|c|}{ c } & \multicolumn{4}{|c|}{$c^{\prime}$} \\
\hline & $\beta$ & $S E$ & $R^{2}$ & $\beta$ & $S E$ & $R^{2}$ & $\beta$ & $S E$ & $R^{2}$ & $\beta$ & $S E$ & $R^{2}$ \\
\hline $\begin{array}{l}\text { Individual Consideration } \\
\text { Leader-Inspired Extra Effort }\end{array}$ & $.491 * *$ & .143 & .135 & & & & & & & & & \\
\hline $\begin{array}{l}\text { Individual Consideration } \\
\text { Closeness }\end{array}$ & & & & $.069 *$ & .101 & .003 & & & & & & \\
\hline $\begin{array}{c}\text { Closeness } \\
\text { Leader-Inspired Extra Effort }\end{array}$ & & & & & & & -.062 & .210 & .006 & & & \\
\hline $\begin{array}{l}\text { Individual Consideration * } \\
\text { Leader-Inspired Extra }\end{array}$ & ness & & & & & & & & & -.112 & .103 & .135 \\
\hline
\end{tabular}

Note. ${ }^{* *} p<0.01, \beta=$ Beta coefficient, $S E$ : Standard Error, $R^{2}=\mathrm{R}$ square. 


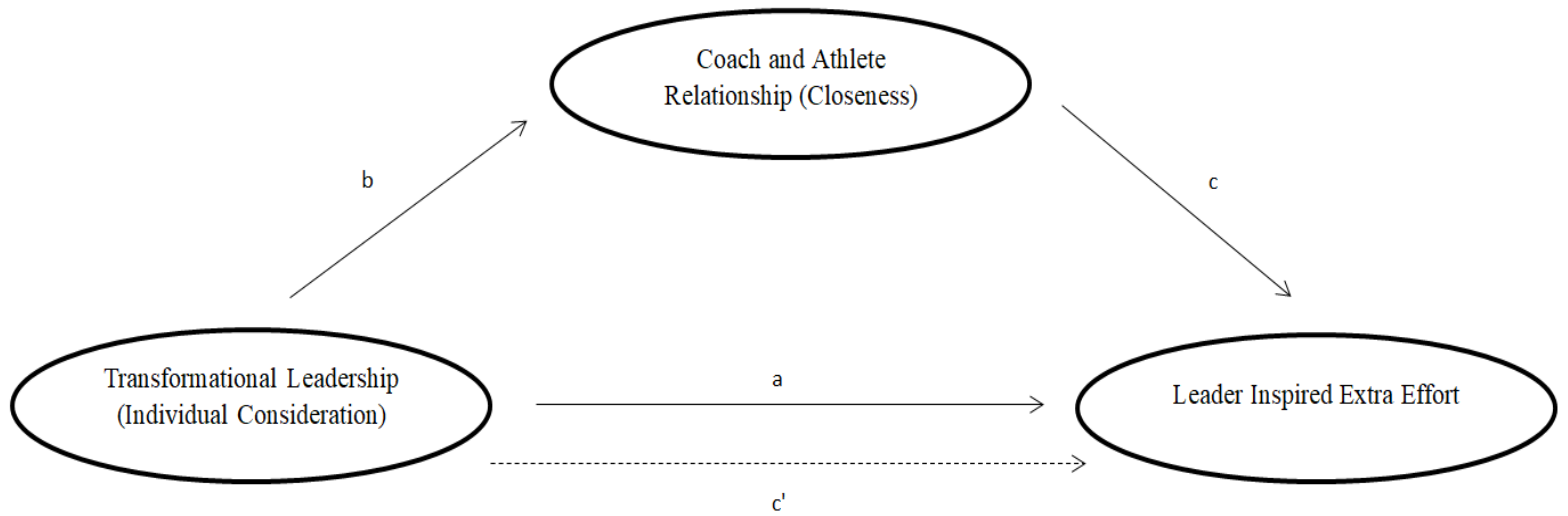

Figure 1. The hypothesized mediating role of coach and athlete relationship between transformational leadership and leader-inspired extra effort.

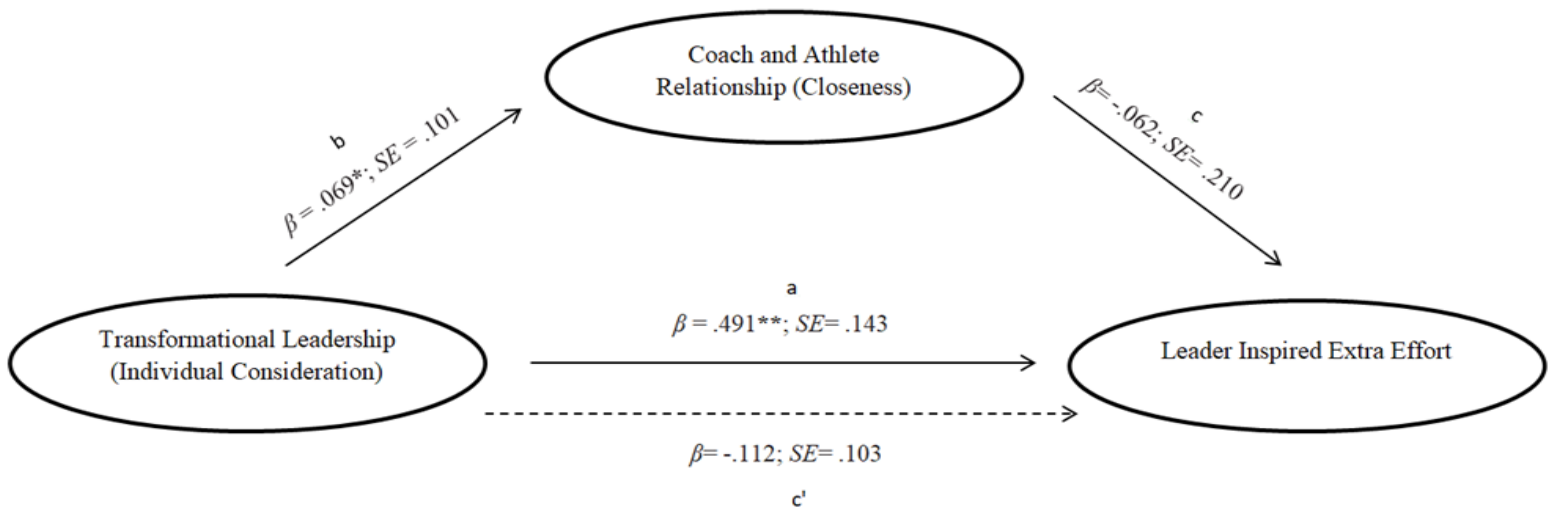

Figure 2. The non-significant mediating role of coach and athlete relationship between transformational leadership and leader-inspired extra effort.

\section{Conclusions}

The aim of this study was to examine the relationship between transformational leader behaviour (namely individual consideration) and leader-inspired extra effort as well as to investigate the mediating role of coach and athlete relationship (closeness). More specifically, it was hypothesized that the closeness (coach and athlete relationship) would fully mediate between transformational leadership behaviour and leader-inspired extra effort. The results demonstrated that transformational leadership was positively associated with leader-inspired extra effort and this relationship was partially mediated by closeness in college basketball players. This finding is in line with previous research $(9,11)$, therefore coaches, practitioners and educators would do well by considering that the full extent of transformational behaviour has an impact on athletic performance. The current study has reviewed the transformational leadership and performance related research in an attempt to assess the implications in the college basketball players. While it is easy to agree with Weinberg and Gould [27] who state that, 'determining what makes effective sports leadership is clearly not a simple process' (p. 213), by examining the theories and research findings from the coaching and transformational leadership literature.

To date, a limited numbers of studies were conducted to explore transformational leadership in sports settings. For example, Cronin, Arthur, Hardy and Callow, [28] found that inside sacrifices mediated the relationship between the transformational leadership behaviour and task cohesion for athletes at the university level $(N=381)$. More specifically, in their investigation results demonstrated that inside sacrifices mediated the relationship between individual consideration, fostering acceptance of group goals, high-performance expectations, appropriate role modelling, inspirational motivation and task cohesion. From the perspective of transformational leadership and task cohesion; Smith and colleagues [29] found a mediational effect between transformational leadership and task cohesion in team sports. While there were some attempts to shed light on the effectiveness of transformational leadership via other psychological aspects of performance, however, the current study was the first attempt to use coach-athlete relationship as the outcome variable to assess its mediational effect between transformational leadership behaviour and the leader-inspired extra effort of college basketball players. In summary, although evidence was presented that coaches' transformational leader behaviour predicted followers' 
effort, the current study did not support full mediation as the coach and athlete relationship when examining the impact that the transformational leader has on the athletic effort.

While this research has strived to evaluate what mediates between transformational leadership and effort by drawing upon research related to leadership and coaching perspectives, this contribution alone is not sufficient in terms of expanding the knowledge domain. There are some limitations that should be considered when interpreting the results and considering future research. While conducting research that recruiting college basketball players as participants were likely to be difficult (given the demands of college sport as a part of educational life). Accordingly, it is necessary to further understand why significant relationship exists between transformational leadership and effort. In addition to this, the lack of research evidence in regard to the relationship between transformational leadership and effort means that there is a scope for researchers to address any number of potentially important areas to further understand why transformational leadership predicts athletic performance. Although common method variance was attempted to be controlled by using varied response forming and providing a psychological barrier between the data collection of all criterion and predictor variables, no further investigation was carried out to assess other psychological aspects in the present research. The number of participants was rather low for all scale validation is also the main limitation of the current study. Future research should seek to use Preacher and Hayes [31] SPSS script as the bootstrapping provides more accurate estimate of the indirect effect with small-to-moderate sample sizes compared to Baron and Kenny's [25] casual steps criteria or the Sobel tests [31, 32].

To date, the research conducted within the sporting domain to discern any mediational role between the transformational leadership and athletic effort is still limited and promising area for future investigations. Due to a lack of research to further understanding of this area, future research should seek to investigate this relationship and the underlying explanatory process. One interesting line of enquiry might be to investigate how coaches attempt to manage any discrepancies between the above and to assess athletes' preferences in regards to leadership style or the relationship between the coaches. For example, Riemer and Chelladurai [30] referred to the 'considerable gap' that existed between the importance attached to leadership in sport and the efforts of researchers to understand it. The conclusions as well as the limitations of this study also bring forth interesting possible avenues for future research that might be needed in relation to the theme of the study. Thus, successful coaches, educators and leaders are common examples of individuals who practice transformational leadership as they engage in sports exchanges that are meant to seek more influence or effect from their constituents, athletes and managers. Therefore, appointing the right coach is vital for the future achievement of athletes and clubs from college to professional settings.

\section{REFERENCES}

[1] Chelladurai P. (1993). Leadership. In: Handbook on Research on Sport Psychology Eds. Singer R.N, Murphey M, and Tennant L.K. New York: Macmillan, 647-671.

[2] Smoll, F.L. \& Smith, R. E. (1989). Leadership behaviours in sport: a theoretical model and research paradigm. Journal of Applied Social Psychology, 19, 1522- 1551.

[3] Jowett, S. (2005). On repairing and enhancing the coach and athlete relationship. In S. Jowett, \& M. Jones (Eds.), the psychology of coaching (pp. 14-26). Leicester: Sport and Exercise Psychology Division, the British Psychological Society.

[4] Vella, S.A., Oades, L.G. \& Crowe, T.P. (2012). 'Validation of the differentiated transformational leadership inventory as a measure of coach leadership in youth soccer', The Sport Psychologist, Vol. 26, No. 2, pp.207-223.

[5] Chellandurai, P. (1984). Leadership in sports. In J. Silva \& R. Weinberg. Psychological Foundations of Sport. Champaign, IL: Human Kinetics.

[6] Crust, L. \& Lawrence, I. (2006). A review of leadership in sport: Implications for football management. Athletic Insight: The Online Journal of Sport Psychology, 8, 28-48.

[7] Case, R., (1984). Leadership in Sport: The situational leadership theory. Journal of Physical Education, Recreation \& Dance, 55(1), 15-16.

[8] Gould, D., Greenleaf, C., Chung, Y., \& Guinan, D. (2002). A survey of U.S. Atlanta and Nagano Olympians: Variables perceived to influence performance. Research Quarterly for Exercise and Sport, 73, 175-186.

[9] Arthur, C.A., Woodman, T., Ong W. C., Hardy, L., \& Ntoumanis, N., (2011). The Role of Athlete Narcissism in Moderating the Relationship between Coaches' Transformational Leader Behaviors and Athlete Motivation. Journal of Sport \& Exercise Psychology, 33, 3-19, Human Kinetics, Inc.

[10] Charbonneau, D., Barling, J., \& Kelloway, K. E. (2001). Transformational leadership and sports performance: The mediating role of intrinsic motivation. Journal of Applied Social Psychology, 31, 1521-1534.

[11] Callow, N., Smith, M., Hardy, L., Arthur, C.A., \& Hardy, J. (2009). Measurement of transformational leadership and its relationship with team cohesion and performance level. Journal of Applied Sport Psychology, 21, 395-412.

[12] Rowold, J. (2006). Transformational and transactional leadership in martial arts. Journal of Applied Sport Psychology, 18, 312-325.

[13] Barling, J., Weber, T., \& Kelloway, E. K. (1996). Effects of transformational leadership training on attitudinal and financial outcomes: A field experiment. Journal of Applied 
Psychology, 81, 827-832.

[14] Bass, B. M., Avolio, B.J., Jung, D. I., \& Berson, Y. (2003). Predicting unit performance by assessing transformational and transactional leadership. Journal of Applied Psychology, 88 (2), 207-218

[15] Kark, R., Shamir, B., \& Chen, G. (2003). The two faces of transformational leadership: Empowerment and dependency. Journal of Applied Psychology, 88(2), 246-255.

[16] Yukl, G. (1999). An evaluation of conceptual weaknesses in transformational and charismatic leadership theories. The Leadership Quarterly, 10, 285-30.

[17] Bass, B.M. (1985). Leadership and Performance beyond Expectations. New York: Freeman and Company.

[18] Bass, B. M. (1998). Transformational leadership: Industry, military, and educational impact. Mahwah, NJ: Erlbaum.

[19] Bycio, P., Hackett, R. D., \& Allen, J. S. (1995). Further assessments of Bass's (1985) conceptualization of transactional and transformational leadership. The Journal of Applied Psychology, 80, 468-478.

[20] Dvir, T., Eden, D., Avolio, B. J., Bass, B. M., \& Shamir, B. (2002). Impact of transformational leadership on follower development and performance: A field experiment. Academy of Management, 45(4), 735-744.

[21] Yammarino, F. J., \& Bass, B. M. (1990). Transformational leadership and multiple levels of analyses. Human Relations, 43, 975-995.

[22] Cronbach, L.J. (1951). Coefficient alpha and the internal structure of tests. Psychometrika, 16, 297-334.

[23] Jowett, S., \& Ntoumanis, N. (2004). The coach-athlete relationship questionnaire (CART-Q): Development and initial validation. Scandinavian Journal of Medicine \&
Science in Sports, 14, 245-257.

[24] Bass, B. M., \& Avolio, B. J. (2005). MLQ: Multifactor Leadership Questionnaire (2nd edition).Redwood City, CA: Mind Garden.

[25] Baron, R. M., \& Kenny, D. A. (1986). The moderator-mediator variable distinction in social psychological research: Conceptual, strategic and statistical considerations. Journal of Personality and Social Psychology, 51, 1173-1182.

[26] Nunnally, J. C. (1978). Psychometric theory (2 ${ }^{\text {nd }}$ edition). New York: McGraw-Hill.

[27] Weinberg, R. S., \& Gould, D. (2003). Foundations of sport and exercise psychology ( $3^{\text {rd }}$ edition). Champaign, IL: Human Kinetics, (p.213).

[28] Cronin, D. L., Arthur, C. Hardy, J. \& Callow, N. (2015). Transformational leadership and task cohesion in sport: The mediating role of inside sacrifice. Journal of Sport and Exercise Psychology, 37, 23-36.

[29] Smith, M. J., Arthur, C. A., Hardy, J., Callow, N., \& Williams, D. (2013). Transformational leadership and task cohesion in sport: The mediating role of intrateam communication. Psychology of Sport and Exercise, 14, 249257.

[30] Riemer, H. A., \& Chelladurai, P. (1995). Leadership and Satisfaction in Athletics.

[31] Preacher, K. J., \& Hayes, A. F. (2008). Asymtotic and resampling strategies for assessing and comparing indirect effects in multiple mediator models. Behavior Research Methods, 40 (3), 879-891.

[32] Courbalay, A., Deroche, T., \& Woodman, T. (2016). Women's greater fear of pain is mediated by neuroticism. Psychologie Française, 61, 153-162. 